\title{
Effect of lipopolysaccharide, skin sensitizers and irritants on thioredoxin-1 expression in dendritic cells: relevance of different signalling pathways
}

\author{
Vera Francisco $\cdot$ Bruno Miguel Neves $\cdot$ Maria Teresa Cruz • \\ Margarida Gonçalo $\cdot$ Américo Figueiredo • \\ Carlos B. Duarte $\cdot$ Maria Celeste Lopes
}

Received: 1 July 2009 / Revised: 19 August 2009 / Accepted: 21 August 2009 / Published online: 16 September 2009

(C) Springer-Verlag 2009

\begin{abstract}
Thioredoxin-1 is a ubiquitous protein involved in phenotypical and functional changes in dendritic cells (DC). We investigated the effect of lipopolysaccharide (LPS), skin sensitizers, and irritants on thioredoxin-1 by Western blot and immunofluorescence and on mRNA by real-time PCR. As DC models, we used a skin DC line and DC derived from human blood monocytes. We observed that all tested chemicals increased thioredoxin-1 expression, which is only transient for irritants, being the strongest effect observed for LPS $(63 \pm 15 \%)$. To address the involvement of thioredoxin-1 in DC maturation, we analysed the effect of an activator of thioredoxin-1 expression, hydrogen peroxide, on CD86 expression, a marker of DC maturation. We found that hydrogen peroxide increases thioredoxin- 1 and CD86 expression reinforcing thioredoxin-1 involvement in DC maturation. Because mitogen-activated protein kinases and PI3K are activated upon DC maturation, we also analysed their involvement in thioredoxin-1 modulation. We verified that LPS-induced upregulation of thioredoxin-1 expression was dependent on PI3K pathway.
\end{abstract}

V. Francisco · B. M. Neves · M. T. Cruz ( $\square)$.

C. B. Duarte - M. C. Lopes

Center for Neuroscience and Cell Biology,

University of Coimbra, 3004-517 Coimbra, Portugal

e-mail: trosete@ff.uc.pt

B. M. Neves · M. T. Cruz • M. C. Lopes

Faculty of Pharmacy, University of Coimbra,

Pólo das Ciências da Saúde, Azinhaga de Santa Comba,

3000-548 Coimbra, Portugal

M. Gonçalo · A. Figueiredo

Department of Dermatology, Faculty of Medicine,

Coimbra's University Hospitals,

Praceta Dr. Mota Pinto, 3004-561 Coimbra, Portugal
Keywords Dendritic cells maturation · Intracellular signalling pathways $\cdot$ Lipopolysaccharide $\cdot$ Skin sensitization · Thioredoxin

\section{Introduction}

Allergic contact dermatitis (ACD), a common occupational and environmental health problem, is a delayed-type hypersensitivity reaction induced by small reactive chemicals following skin contact $[19,35]$. A critical step in the induction of ACD is the activation and subsequent migration of immature dendritic cells (DC) of the skin, namely the Langerhans cells (LC). LC typify the sentinel role of immature DC, translating changes in their local microenvironment into specific immune responses. Following an encounter with skin sensitizers, LC become activated, migrate to lymph nodes and mature into immunostimulatory DC capable of presenting antigen to naïve $\mathrm{T}$ cells $[10,50]$. During maturation, $\mathrm{LC}$ experiment morphological, functional and phenotypical changes, such as alteration of surface markers $[2,20,58]$, production of cytokines and chemokines $[3,16$, $20]$ and the induction of signal-transduction pathways [20, 46]. Lipopolysaccharide (LPS) and skin sensitizers, in contrast to irritants, have been described to stimulate DC maturation $[3,9,13,16,28,57,60,64]$. However, the exact cellular and molecular mechanisms of DC activation are not yet fully understood, being this knowledge crucial to elucidate the mechanisms involved in the acquisition of skin sensitization.

Thioredoxin (Trx)-1, a ubiquitous protein with a conserved dithiol motif in the active site, is involved in the maintenance of proteins in their reduced state. Trx-1 has an important role in defence against cellular oxidative stress $[8,65]$, being its expression regulated by nuclear factor 
erythroid-derived 2-related factor (Nrf2)/antioxidant responsive element (ARE) pathway [29, 67]. Recently, Nrf2/ARE regulatory pathway has been proposed for the screening of the sensitization potential of novel chemicals [1, 42]. Trx-1 functions [8] also include control of growth, regulation of the activation of several transcription factors (Nrf2, nuclear factor $[\mathrm{NF}]-\kappa \mathrm{B}$, activator protein $[\mathrm{AP}]-1$ and p53), modulation of apoptosis by direct inhibition of apoptosis signal-regulating kinase 1 (ASK1) [36, 51] and also co-cytokine and chemokine activity [11]. Hence, beyond its intrinsic antioxidant activity against oxidative stress induced by oxidants and electrophiles such as skin sensitizers, Trx-1 has also a signalling intermediate role that could be responsible for phenotypical and functional changes in DC following exposure to chemical sensitizer. Accordingly, it was previously demonstrated that Trx genes were upregulated in DC after treatment with the DC maturation inducer agent LPS [45, 55] and the strong allergen 2,4-dinitrobenzene sulphonic acid [23, 48].

Previous studies, performed by us and other authors, reported the involvement of intracellular signalling pathways, namely mitogen-activated protein kinases (MAPK), phosphoinositide-3-OH kinase (PI3K)-Akt and the transcription factor $\mathrm{NF}-\kappa \mathrm{B}$, in the survival and maturation of DC [7, 9, 14-17, 37, 38, 43, 46, 64]. Accordingly, it was previously demonstrated by us and other authors that LPS and skin sensitizers activate MAPK signalling pathways in DC [4, 31, 37, 40, 57]. In addition, MAPK are involved in the induction of Nrf2/ARE-dependent gene expression [66]. Therefore, analysis of intracellular signalling pathways, particularly their involvement in Trx-1 protein expression, could provide a promising tool for the elucidation of the DC maturation process.

To understand the skin sensitization process and the intracellular mechanisms involved in DC maturation, we investigated: (1) the effect of LPS, skin sensitizers with different chemical structures and with different potencies, namely 2,4-dinitrofluorobenzene (DNFB), 1,4-phenylenediamide (PPD) and nickel sulphate $\left(\mathrm{NiSO}_{4}\right)$, and irritants with different structures, in particular sodium dodecyl sulphate (SDS) and benzalkonium chloride (BC) in Trx-1 protein expression in DC; (2) the correlation between thioredoxin-1 expression and DC maturation, by addressing the role of hydrogen peroxide, an activator of thioredoxin1[49], on the conventional marker of DC maturation CD86 [20], and recently demonstrated by us to be upregulated in a mouse skin DC line by LPS [44]; (3) finally, we investigated which intracellular signalling pathways were responsible for Trx-1 protein increase induced by LPS. As experimental DC cell models, we used the fetal skinderived dendritic cell line (FSDC) and DC derived from human peripheral blood monocyte (MoDC). FSDC is a skin DC precursor with morphological, phenotypical and functional characteristics of LC [24] and, in contrast to other DC cell lines, did not require exogenous growth factors for their continued proliferation, when cultured in serum-containing medium. As major findings, we observed that (1) all tested chemicals increased thioredoxin-1 expression, which is only transient for irritants, being the strongest effect observed for LPS; (2) there is a correlation between thioredoxin-1 expression and DC maturation; (3) the upregulation of thioredoxin-1 expression induced by LPS was dependent on the PI3K pathway.

\section{Materials and methods}

\section{Materials}

Iscove's modified Dulbecco's medium (IMDM), RPMI1640, DNFB, SDS, PPD, dexamethasone, cyclosporin A and Tween-20 were obtained from Sigma-Aldrich Química (Madrid, Spain). $\mathrm{NiSO}_{4}$ and $\mathrm{BC}$ were purchased from Sigma Chemical Co. (Madrid, Spain). LPS from Escherichia coli (serotype 026:B6) was from Sigma Chemical Co. (St Louis, MO, USA). LY294002 and SP600125 were from Calbiochem (San Diego, CA, USA). SB203580 was a kind gift of Dr J.L. Adams from SmithKline Pharmaceuticals (King of Prussia, PA, USA) and PD098059 was obtained from RBI (Natick, MA, USA). Fetal calf serum and trypsin were purchased from Gibco (Paisley, UK) and human GM-CSF and IL-4 were from PeproTech (London, UK). The protease and phosphatase inhibitor cocktails were obtained from Roche (Amadora, Portugal). Lymphoprep was from Axis-Shield (Oslo, Norway) and the MACS colloidal supermagnetic microbeads conjugated with antihuman CD14 monoclonal antibody (CD14 microbeads) were purchased from Miltenyi Biotec Inc. (Bergisch Gladbach, Germany). Acrylamide was obtained from Promega (Madison, WI, USA) and the polyvinylidene difluoride (PVDF) membranes were from Millipore Corporation (Bedford, MA, USA). The rabbit polyclonal antibody against CD86 was from Santa Cruz Biotechnology (Santa Cruz, CA, USA). The rabbit polyclonal antibody against Trx-1 was purchased from Abcam (Cambridge, UK) and the mouse monoclonal anti- $\beta$-tubulin I antibody was from Sigma-Aldrich Química (Madrid, Spain). The alkaline phosphatase-linked secondary antibodies and the enhanced chemifluorescence (ECF) reagent were obtained from GE Healthcare (Carnaxide, Portugal). The Vectashield mounting medium was purchased from Vector, Inc. (Burlingame, CA, USA) and Alexa 488-conjugated goat anti-rabbit antibody was from Molecular Probes (Eugene, OR, USA). TRIzol reagent was purchased from Invitrogen (Barcelona, Spain). iScript kit and SYBR Green were obtained from Bio-Rad (Amadora, Portugal). Primers were from MWG 
Biotech (Ebersberg, Germany). All other reagents were from Sigma Chemical Co. (Madrid, Spain) or from Merck (Darmstadt, Germany).

\section{Cell culture}

The FSDC cell line, kindly supplied by Dr G. Girolomoni (Laboratory of Immunology, Istituto Dermopatico dell'Immacolata, IRCCS, Rome, Italy), has a surface phe-

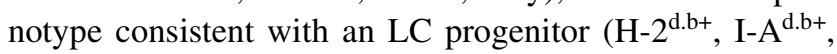

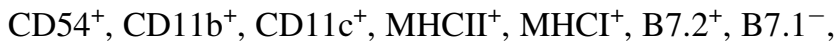
$\mathrm{CD}_{4} 4^{+}, \mathrm{B} 220^{-}, \mathrm{CD}^{-}$) [24], a phenotype confirmed in our laboratory for the most relevant surface markers [44]. FSDC was cultured in IMDM, supplemented with $10 \%$ (v/ v) heat-inactivated fetal calf serum, $35.9 \mathrm{mM}$ sodium bicarbonate, $1 \%(\mathrm{w} / \mathrm{v})$ glutamine, $100 \mathrm{U} / \mathrm{ml}$ penicillin and $100 \mu \mathrm{g} / \mathrm{ml}$ streptomycin.

MoDC were obtained from $\mathrm{CD} 14^{+}$monocytes that were generated from peripheral blood mononuclear cells, as described previously [43]. Blood was collected from healthy human donors after their informed consent. The $\mathrm{CD} 4^{+}$monocytes were cultured in modified RPMI-1640 supplemented with $10 \%(\mathrm{v} / \mathrm{v})$ heat-inactivated fetal calf serum, $100 \mathrm{U} / \mathrm{ml}$ penicillin, $100 \mu \mathrm{g} / \mathrm{ml}$ streptomycin, $800 \mathrm{U} / \mathrm{ml} \mathrm{IL-4}$ and 1,000 U/ml GM-CSF. After 7 days of culture, the cell phenotype is consistent with an immature DC phenotype: HLA-DR ${ }^{+}, \mathrm{CD}_{1} \mathrm{a}^{+}, \mathrm{CD} 83^{-}, \mathrm{CD} 80^{\text {low }}$ and CD86 ${ }^{\text {low }}[26]$.

\section{Chemical treatment}

For determination of Trx-1 protein levels by Western blot analysis, FSDC was plated at $0.5 \times 10^{6}$ cells $/ \mathrm{ml}$ in 12 -well microplates or at $0.33 \times 10^{6}$ cells $/ \mathrm{ml}$ in 24 -well microplates and then incubated with the chemicals for 24 and $48 \mathrm{~h}$, respectively. MoDC were plated at $0.3 \times 10^{6} \mathrm{cells} / \mathrm{ml}$ in 24-well plates. Cells were incubated with $5 \mu \mathrm{g} / \mathrm{ml} \mathrm{LPS}$, or with the skin sensitizers DNFB $(1 \mu \mathrm{g} / \mathrm{ml})$, PPD $(50 \mu \mathrm{g} / \mathrm{ml})$ and $\mathrm{NiSO}_{4}(50 \mu \mathrm{g} / \mathrm{ml})$, or with the irritants SDS $(50 \mu \mathrm{g} / \mathrm{ml})$ and $\mathrm{BC}(1 \mu \mathrm{g} / \mathrm{ml})$, or with the $\operatorname{Trx}$ activator $\mathrm{H}_{2} \mathrm{O}_{2}(5$ or $20 \mu \mathrm{M}$ ), for 24 and $48 \mathrm{~h}$. SDS, BC, PPD and $\mathrm{NiSO}_{4}$ were dissolved in PBS, while DNFB and DCNB were first solubilised in dimethyl sulphoxide and subsequent dilutions were performed in PBS. The final concentration of dimethyl sulphoxide never exceeded $0.01 \%(\mathrm{v} / \mathrm{v})$, and was without effect on cell viability and on Trx-1 expression (data not shown). To investigate the signalling pathways involved in Trx-1 protein expression induced by LPS, cells were incubated with $5 \mu \mathrm{g} / \mathrm{ml}$ LPS alone or in the presence of the different signalling pathways inhibitors for $48 \mathrm{~h}$. LY294002 $(2.5 \mu \mathrm{M})$ was used as PI3K inhibitor, SB203580 $(20 \mu \mathrm{M})$ as p38 MAPK inhibitor, PD098059 $(20 \mu \mathrm{M})$ as extracellular signal-regulated protein kinase (ERK)1/2 inhibitor and
SP600125 $(1 \mu \mathrm{M})$ as c-Jun N-terminal kinase (JNK) inhibitor. In addition, the effect of the immunomodulators such as dexamethasone $(5 \mu \mathrm{M})$ and cyclosporin $\mathrm{A}(1 \mu \mathrm{M})$ was also evaluated on Trx-1 protein expression induced by LPS. Dexamethasone and cyclosporin A are immunosuppressors that inhibit the transcription factor NF- $\kappa \mathrm{B}$ in FSDC, as previously demonstrated by us $[17,63]$.

For immunocytochemistry analysis, FSDC was plated at $0.1 \times 10^{6}$ cells/well on glass coverslips. To analyse the Trx-1 immunoreactivity, cells were then incubated with $5 \mu \mathrm{g} / \mathrm{ml}$ LPS, $1 \mu \mathrm{g} / \mathrm{ml}$ DNFB or $1 \mu \mathrm{g} / \mathrm{ml}$ BC for $48 \mathrm{~h}$. To investigate the surface levels of CD86, cells were incubated with $5 \mu \mathrm{g} / \mathrm{ml}$ LPS or $20 \mu \mathrm{M} \mathrm{H}_{2} \mathrm{O}_{2}$ for $24 \mathrm{~h}$.

For determination of the Trx-1 mRNA levels by RTPCR, FSDC was plated at $0.5 \times 10^{6} \mathrm{cell} / \mathrm{ml}$ in six-well microplates and then incubated with $5 \mu \mathrm{g} / \mathrm{ml} \mathrm{LPS}, 1 \mu \mathrm{g} / \mathrm{ml}$ DNFB, $50 \mu \mathrm{g} / \mathrm{ml} \mathrm{NiSO}{ }_{4}$ or $50 \mu \mathrm{g} / \mathrm{ml} \mathrm{SDS}$ for $24 \mathrm{~h}$.

Concentrations of the chemicals used to perform the experiments (optimal concentrations) were those that induced until $30 \%$ of cytotoxicity, evaluated by the 3-(4,5dimethyl-2-thiazolyl)-2,5-diphenyl-2H-tetrazolium bromide reduction assay (data not shown), since it has been described that some degree of cytotoxicity may play an important role in DC activation [27, 52]. Control experiments were performed with non-treated cells.

Western blot analysis

To prepare total cell lysates for Western blot analysis, cells were harvested in ice-cold lysis buffer containing $0.25 \mathrm{M}$ sucrose, $10 \mathrm{mM}$ Tris- $\mathrm{HCl}$ (pH 7.5), $1 \mathrm{mM}$ ethylenediaminetetraacetic acid, $1 \mathrm{mM}$ dithiothreitol, protease inhibitor cocktail and phosphatase inhibitor cocktail. Cell lysates were incubated $30 \mathrm{~min}$ on ice, and then sonicated to disrupt the cells. Protein concentration of the cell lysates was determined by the bicinchoninic acid protein assay. Cell lysates were then denatured and either used immediately for SDSPAGE electrophoresis, or frozen at $-20^{\circ} \mathrm{C}$ until use.

Briefly, equivalent amounts of protein $(5-20 \mu \mathrm{g})$ were separated by electrophoresis on a $12 \%(\mathrm{v} / \mathrm{v})$ SDS-polyacrylamide gel and transferred to PVDF membranes. The membranes were saturated with $5 \%(\mathrm{w} / \mathrm{v})$ fat-free dry milk in Tris-buffered saline, containing $0.1 \%(\mathrm{v} / \mathrm{v})$ Tween-20 (TBS-T) for $1 \mathrm{~h}$ at room temperature. The levels of Trx-1 and CD86 protein were detected using a rabbit anti-thioredoxin antibody $(1: 2,000)$ and a rabbit anti-CD86 antibody (1:200), respectively, for $1 \mathrm{~h}$ at room temperature, followed by incubation with an alkaline phosphatase-conjugated anti-rabbit antibody $(1: 20,000)$. The immune complexes were detected using the ECF system and the membranes were scanned for blue excited fluorescence on the Storm 860 (GE Healthcare). The generated signals were quantified by scanning the membranes with a fluorescence scanner 
and analysed using the software ImageQuant $\mathrm{TL}^{\circledR}$. To demonstrate equivalent protein loading, membranes were stripped and reprobed with a monoclonal anti- $\beta$-tubulin I antibody $(1: 20,000)$, followed by incubation with an alkaline phosphatase-conjugated anti-mouse antibody $(1: 20,000)$. All the antibodies were prepared in $1 \%(\mathrm{w} / \mathrm{v})$ fat-free dry milk in TBS-T.

\section{Immunofluorescence assay}

After FSDC incubation with chemicals, cells were fixed and permeabilized with cold methanol:acetone (1:1) for 10 min. For immunocytochemistry detection of CD86 on the surface level, the cells were only fixed with paraformaldehyde $4 \%(\mathrm{w} / \mathrm{v})$ in PBS. Non-specific binding was blocked by incubating the cells with PBS supplemented with $1 \%(\mathrm{w} / \mathrm{v}) \mathrm{BSA}$ for $45 \mathrm{~min}$ at room temperature. Cells were then incubated with a rabbit polyclonal anti-Trx-1 antibody (1:200) for $2 \mathrm{~h}$ at room temperature or with a rabbit anti-CD86 antibody $(1: 25)$ overnight at $4^{\circ} \mathrm{C}$, followed by incubation with Alexa 488-conjugated goat anti-rabbit antibody (1:500) for $45 \mathrm{~min}$. Antibodies were diluted in PBS supplemented with $0.5 \%(w / v)$ BSA. After a washing step, a DAPI solution $(0.1 \mu \mathrm{g} / \mathrm{ml})$ was added to cells for

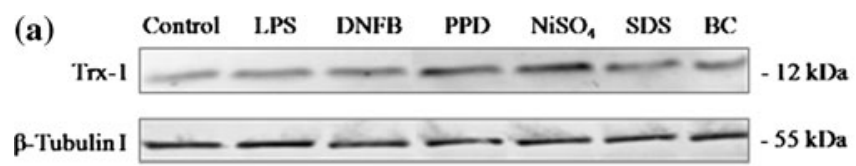

(b)

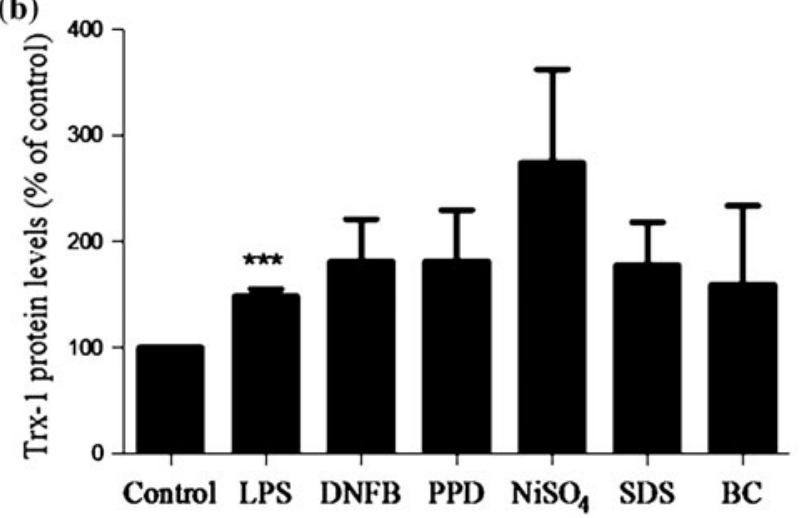

Fig. 1 Modulation of Trx-1 expression by LPS, skin sensitizers and irritants, after $24 \mathrm{~h}$ of DC stimulation. FSDC (a) was incubated, in culture medium, in the absence (control), or in the presence of $5 \mu \mathrm{g} / \mathrm{ml}$ LPS, $1 \mu \mathrm{g} / \mathrm{ml}$ DNFB, $50 \mu \mathrm{g} / \mathrm{ml}$ PPD, $50 \mu \mathrm{g} / \mathrm{ml} \mathrm{NiSO}_{4}, 50 \mu \mathrm{g} / \mathrm{ml}$ SDS or $1 \mu \mathrm{g} / \mathrm{ml} \mathrm{BC}$, for $24 \mathrm{~h}$. Equal amounts of protein, obtained from total cell extracts, were electrophoresed through SDS-PAGE, transferred to PVDF membranes and subjected to Western blot analysis using an anti-Trx-1 antibody. To ensure that there were similar amounts of protein in each sample, the membranes were stripped, and reprobed with a monoclonal anti- $\beta$-tubulin I $(1: 20,000)$ followed by incubation with an alkaline phosphatase-conjugated anti-mouse antibody (1:20,000).
$1 \mathrm{~min}$ to stain the nucleus. The coverslips were mounted with Vectashield mounting medium. Negative control experiments were performed as described above, except for the omission of the primary antibody, and resulted in weak non-specific staining. Fluorescence labelling was visualised in a Zeiss Axiovert 200 microscope, and images acquired with a coupled AxioCamHR camera and analysed with AxioVision v.4.5 software. In each experiment, the optimal acquisition parameters were defined for the condition that had the highest fluorescence and then maintained for all the other conditions, within the same experiment.

RNA isolation, cDNA synthesis and real-time PCR

Total RNA was isolated by TRIzol method. Briefly, after chemical stimulation, cells were scrapped in TRIzol. Chloroform was added, and the samples were centrifuged at $12,000 \mathrm{~g}$, for $15 \mathrm{~min}$ at $4^{\circ} \mathrm{C}$ to separate the phases. The aqueous phase was transferred to a fresh tube and the RNA precipitated by mixing with isopropyl alcohol. After centrifugation at $12,000 \mathrm{~g}$, for $10 \mathrm{~min}$ at $4^{\circ} \mathrm{C}$, the supernatant was removed and the RNA pellet washed with $75 \%$ ethanol. The RNA was then resuspended in RNase-free water. The amount and purity of the RNA samples was evaluated by
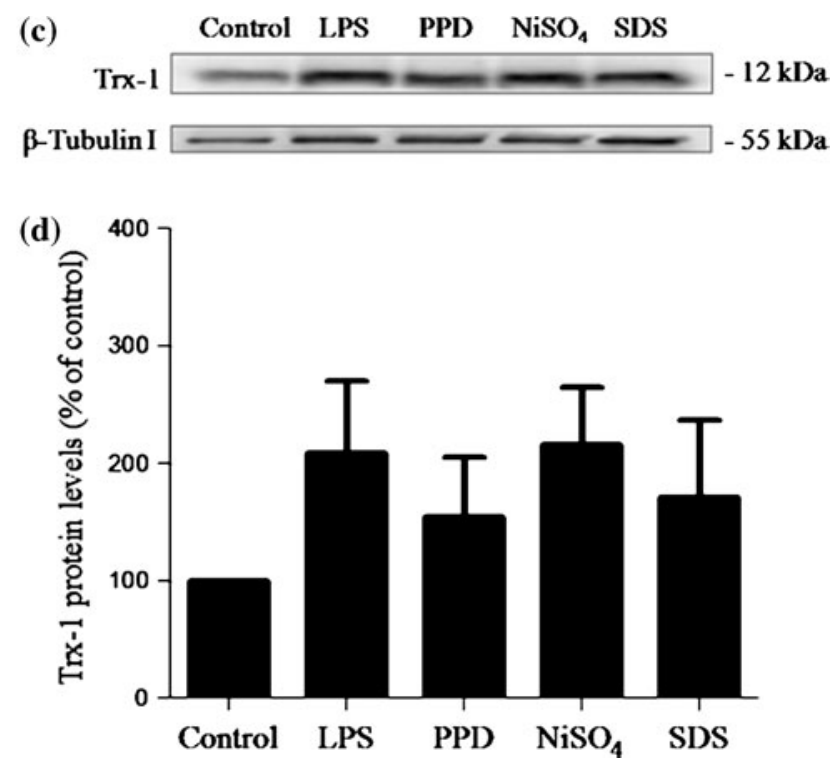

b The blots were quantified and the results were expressed as \% of Trx1 protein levels relatively to the control and each value represents the mean \pm SEM of three to four independent experiments. c, d The results of Western blot analysis obtained in FSDC was confirmed in MoDC. MoDC, obtained by culturing human monocytes in GM-CSF and IL-4-supplemented culture medium for 7 days, were incubated, in culture medium, in the absence (control), or in the presence of $5 \mu \mathrm{g} / \mathrm{ml}$ LPS, $50 \mu \mathrm{g} / \mathrm{ml}$ PPD, $50 \mu \mathrm{g} / \mathrm{ml} \mathrm{NiSO}_{4}$ or $50 \mu \mathrm{g} / \mathrm{ml} \mathrm{SDS}$, for $24 \mathrm{~h}$. For MoDC (d), each value represents the mean \pm SEM of two independent experiments. The results were statistically compared using Student's $t$ test $(* * * P<0.001$ as compared to the control) 
spectrophotometry, using NanoDrop ND-1000 Spectrophotometer (NanoDrop Technologies Inc.). The RNA was stored at $-80^{\circ} \mathrm{C}$. Reverse transcription of RNA was performed using iScript ${ }^{\mathrm{TM}}$ select cDNA synthesis kit. In all reactions, cDNA was synthesised in $20 \mu \mathrm{l}$ using $1 \mu \mathrm{g}$ of total RNA and $2 \mu \mathrm{l}$ of random primers. The resulting cDNA was stored at $-20^{\circ} \mathrm{C}$ until assayed by real-time PCR using SYBR Green fluorescence dye on a iCycler iQ real-time PCR detection system. Fifty nanograms of cDNA was used in the real-time PCR reaction mixture that also includes forward and reverse primers $(250 \mathrm{nM})$ and the SYBR Green Supermix $(2 \times)$. cDNAs of the two housekeeping genes HPRT1 and $\beta$-actin, used as endogenous controls, and Trx1 were amplified by PCR using specific oligonucleotide primers selected within the coding regions of the genes. The primers were designed using Beacon Designer 7 software (Premier Biosoft International). Trx-1 primers used

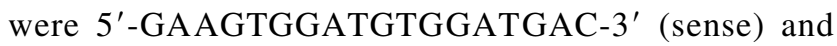
5'-AGGCATATTCAGTAATAGAGG-3' (antisense), designed to produce a 151-bp product; HPRT1 primers used were 5'-GTTGAAGATATAATTGACACTG-3' (sense) and 5'-GGCATATCCAACAACAAAC-3' (antisense), designed to produce a 180 -bp product; and $\beta$-actin primers used were 5'-GTGCGTGACATCAAAGAG-3' (sense) and 5'-GCCACAGGATTCCATACC-3' (antisense), designed to produce a 195-bp product. Real-time PCR was performed in My Cycler iQ5 (Bio-Rad) for 40 cycles, after an initial incubation for $3 \mathrm{~min}$ at $95^{\circ} \mathrm{C}$. Each cycle consisted of a denaturation step during $10 \mathrm{~s}$ at $95^{\circ} \mathrm{C}$, an annealing step during $30 \mathrm{~s}$ at $55^{\circ} \mathrm{C}$ and an elongation step during $30 \mathrm{~s}$ at $72^{\circ} \mathrm{C}$. The SYBR Green fluorescence was detected at the end of each annealing step and the specificity of the amplification products was checked by the melting curve analysis. The quantification data were then analysed by Vandesompele method [59].

\section{Statistics}

The results are expressed as mean \pm SEM of the indicated number of experiments. The statistical analysis was performed using Student's $t$ test or using one-way ANOVA with Dunnett's post test. The significance level was $* P<0.05, * * P<0.01, * * * P<0.001$.

\section{Results}

Modulation of Trx-1 protein levels by LPS, skin sensitizers and irritants in $\mathrm{DC}$

The effect of LPS, skin sensitizers and irritants on Trx-1 protein levels was evaluated by Western blot analysis, after FSDC and MoDC exposure to the chemicals for $24 \mathrm{~h}$. In
FSDC (Fig. 1a), LPS increased the Trx-1 protein levels by $49 \pm 7 \%(* * * P<0.001)$. All the skin sensitizers, namely DNFB, PPD and $\mathrm{NiSO}_{4}$, and the irritants SDS and BC increased the Trx-1 protein levels, although without statistical significance (Fig. 1b). Therefore, the Trx-1 protein levels were not differentially modulated, in FSDC, by skin sensitizers or irritants after $24 \mathrm{~h}$ of cell stimulation. As shown in Fig. 1c, d, the exposure of MoDC, for $24 \mathrm{~h}$, to LPS, PPD, $\mathrm{NiSO}_{4}$ and SDS also increased the Trx-1 protein levels confirming the pattern of Trx-1 expression observed in FSDC.

Next, we investigated Trx-1 protein levels, in FSDC, after exposure to the same chemicals for $48 \mathrm{~h}$, by Western blot analysis (Fig. 2). LPS increased Trx-1 protein levels by $63 \pm 15 \%(* * P<0.01)$. Trx-1 protein levels were also increased after stimulation with DNFB, PPD and $\mathrm{NiSO}_{4}$, although without statistical significance. In contrast, SDS and BC did not modify Trx-1 protein levels when compared with control.

To confirm the Western blot results, we also analysed the effect of LPS, the skin sensitizer DNFB and the irritant BC on the cellular distribution of Trx-1 protein, using immunofluorescence (Fig. 3). According to the results obtained by Western blot analysis, LPS and DNFB upregulate Trx-1
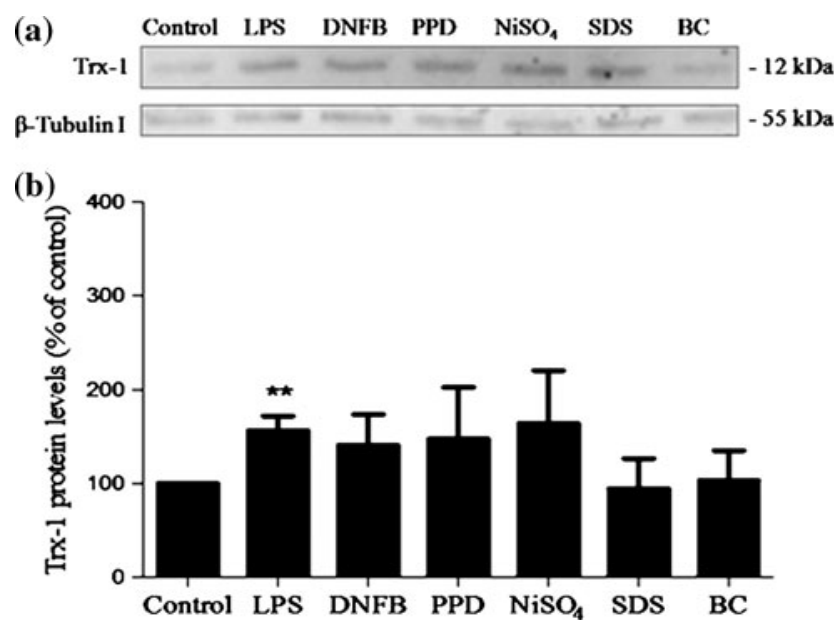

Fig. 2 Modulation of Trx-1 protein levels induced by LPS, skin sensitizers and irritants after $48 \mathrm{~h}$ of FSDC stimulation. a FSDC was incubated in culture medium in the absence (control), or in the presence of $5 \mu \mathrm{g} / \mathrm{ml} \mathrm{LPS}, 1 \mu \mathrm{g} / \mathrm{ml}$ DNFB, $50 \mu \mathrm{g} / \mathrm{ml} \mathrm{PPD}, 50 \mu \mathrm{g} / \mathrm{ml} \mathrm{NiSO}_{4}, 50 \mu \mathrm{g} /$ $\mathrm{ml} \mathrm{SDS}$ or $1 \mu \mathrm{g} / \mathrm{ml} \mathrm{BC}$, for $48 \mathrm{~h}$. Total cell extracts were electrophoresed through SDS-PAGE, transferred to PVDF membranes and subjected to Western blot analysis using an anti-Trx-1 antibody. To ensure that there were similar amounts of protein in each sample, the membranes were stripped, and reprobed with a monoclonal anti- $\beta$-tubulin I antibody $(1: 20,000)$ followed by incubation with an alkaline phosphatase-conjugated anti-mouse antibody $(1: 20,000)$. b The blots were quantified and the results were expressed as $\%$ of Trx-1 protein levels relatively to the control. Each value represents the mean \pm SEM of three to eight independent experiments and the results were statistically compared using Student's $t$ test $(* * P<0.01$ as compared to the control) 
Fig. 3 Immunofluorescence analysis of the effect of LPS, skin sensitizers and irritants on Trx-1 protein levels. FSDC was subjected to immunostaining using an anti-Trx-1 antibody. The images shown are representative of two individual experiments yielding similar results (magnification $\times 630$ )
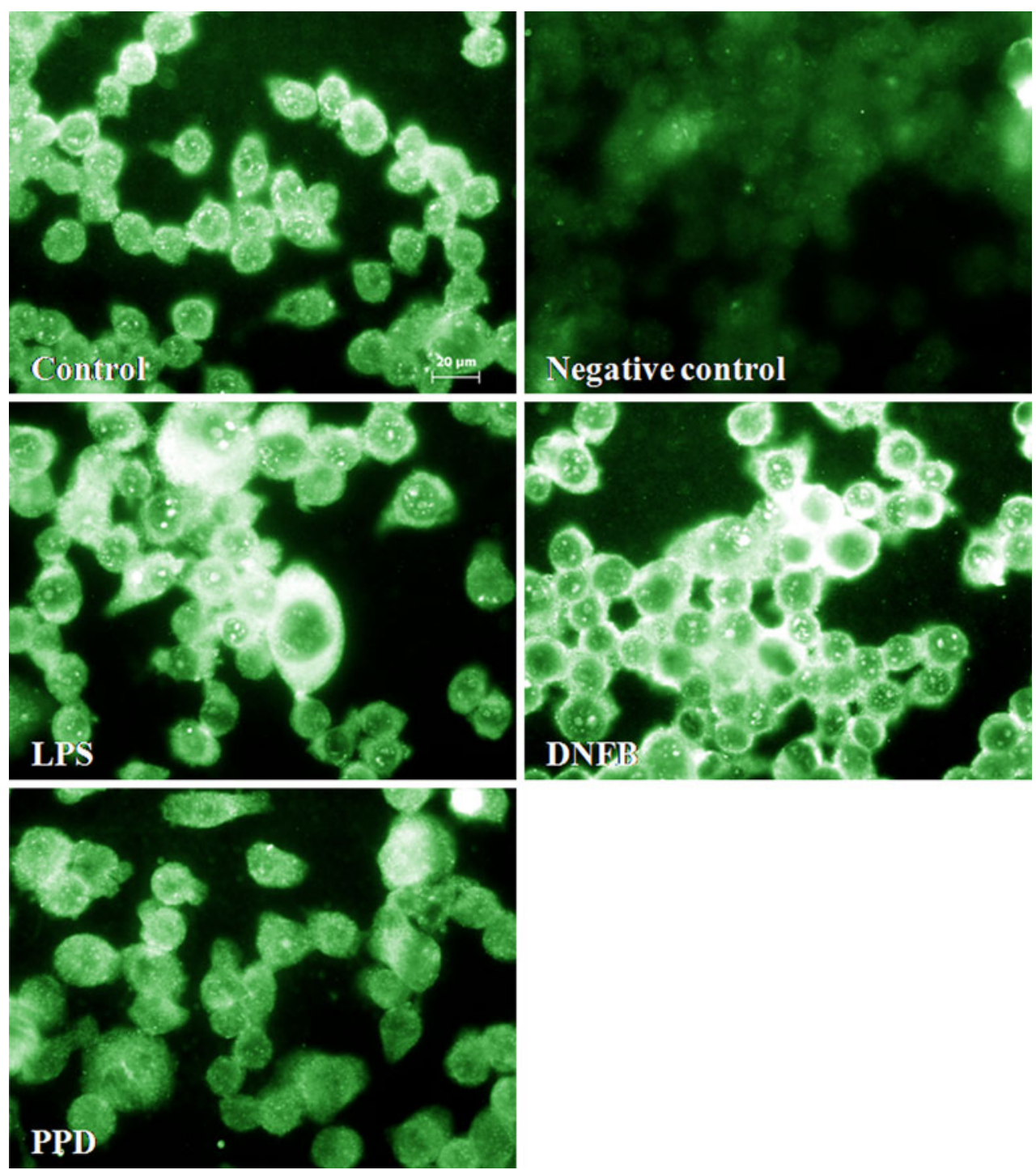

immunoreactivity, in contrast to BC which has no effect, yielding similar results to the control assay. The increases in Trx-1 immunoreactivity, induced by LPS and DNFB, were predominantly observed in the cytoplasm. Negative control experiment resulted in a weak non-specific staining (data not shown). Therefore, LPS and skin sensitizers increased Trx-1 protein levels after $24 \mathrm{~h}$, being this effect still present at $48 \mathrm{~h}$, whereas the increase in Trx-1 protein levels induced by irritants seem to be transient in time. These results suggest that LPS, skin sensitizers and irritants differentially modulates Trx-1 protein levels in FSDC.

Modulation of Trx-1 mRNA expression induced by LPS, skin sensitizers and irritants

Because protein levels are regulated both by protein degradation and by synthesis of new protein, we investigated the effect of LPS, skin sensitizers (DNFB and $\mathrm{NiSO}_{4}$ ) and irritant SDS on the synthesis of new protein, through evaluation of the Trx-1 mRNA levels by real-time PCR analysis (Fig. 4). LPS and $\mathrm{NiSO}_{4}$ increased the Trx-1 mRNA expression by $1.73 \pm 0.21(* P<0.05)$ and $1.91 \pm 0.33$ $(* P<0.05)$ fold, respectively, after $24 \mathrm{~h}$ of FSDC stimulation. Both DNFB (1.16 \pm 0.29 fold) and SDS (1.12 \pm 0.21 fold) had no effect on Trx-1 mRNA expression. To determine housekeeping genes, a panel of six possible genes was analysed. Using the GenEx software (Multi D; Analyser. AB), HPRT1 and $\beta$-actin were selected as the two most stable for the treatment condition used (data not shown).

Effect of hydrogen peroxide on Trx-1 protein expression and on DC maturation

The effect of LPS and different concentrations of $\mathrm{H}_{2} \mathrm{O}_{2}$ on Trx-1 and CD86 protein levels were evaluated by Western blot analysis after FSDC exposure to the chemicals for 24 


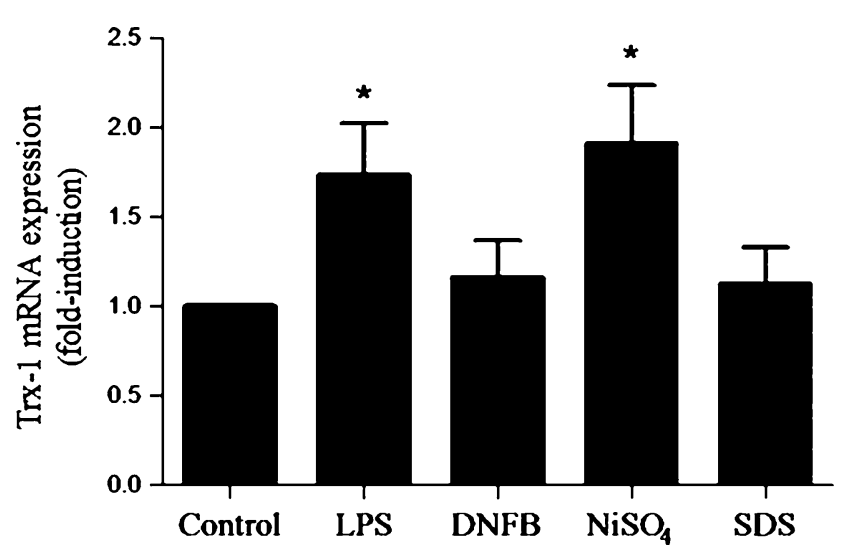

Fig. 4 Modulation of Trx-1 mRNA expression induced by LPS, skin sensitizers and irritants, after $24 \mathrm{~h}$ of FSDC stimulation. FSDC was incubated in culture medium in the absence (control) or in the presence of $5 \mu \mathrm{g} / \mathrm{ml} \mathrm{LPS,} 1 \mu \mathrm{g} / \mathrm{ml} \mathrm{DNFB,} 50 \mu \mathrm{g} / \mathrm{ml} \mathrm{NiSO}_{4}$ or $50 \mu \mathrm{g} / \mathrm{ml} \mathrm{SDS}$, for $24 \mathrm{~h}$, and then analysed for Trx-1 mRNA expression. The results were expressed as fold induction of Trx-1 mRNA expression relatively to control. Each value represents the mean \pm SEM of four independent experiments and the results were statistically compared using Student's $t$ test $(* P<0.05$ as compared to the control)

and $48 \mathrm{~h}$ (Fig. 5a, b). Our results demonstrated that the two $\mathrm{H}_{2} \mathrm{O}_{2}$ concentrations used increased both Trx-1 and CD86 expression. Because CD86 is a DC co-stimulatory molecule, we also verified its upregulation at the surface by performing immunocytochemistry in non-permeabilized cells (Fig. 5c). Our results demonstrated that both LPS and the Trx activator, $\mathrm{H}_{2} \mathrm{O}_{2}$, increased the surface levels of CD86 after $24 \mathrm{~h}$ of DC stimulation.

Intracellular signalling pathways involved in the increase of Trx-1 protein levels induced by LPS

The previous results demonstrated that LPS increased significantly Trx-1 protein levels in FSDC, after 24 and $48 \mathrm{~h}$ of stimulation and Trx-1 mRNA expression also increased after $24 \mathrm{~h}$ of exposure to LPS. We have recent data demonstrating that LPS induced an early activation of Akt, NF- $\kappa \mathrm{B}$ and MAPKs signalling pathways in FSDC [44]. Therefore, we investigated the involvement of these signalling pathways on the modulation of Trx-1 protein levels induced by LPS, after 48 h of cell stimulation, by Western blot. For this purpose, cells were incubated with LPS alone or in the presence of different signalling pathway inhibitors (Fig. 6).

Lipopolysaccharide induced an increase in Trx-1 protein levels by $63 \pm 15 \%(* * P<0.01)$, which was not inhibited by the intracellular signalling pathways inhibitors SB203580, PD098059 and SP600125. On the other hand, the PI3K inhibitor LY294002 induced an increase in the Trx-1 protein levels by $98.1 \%(* P<0.05)$, when compared with LPS alone. Neither dexamethasone nor cyclosporin A, immunosuppressors that inhibit the transcription factor $\mathrm{NF}-\kappa \mathrm{B}$ in
FSDC, as previously demonstrated by us [17, 63], had an effect on Trx-1 protein levels in LPS-stimulated cells.

These results indicated that the PI3K-Akt signalling pathway and not the MAPKs signalling pathways or NF- $\kappa \mathrm{B}$ is involved in the modulation, in particular the inhibition, of Trx-1 protein levels induced by LPS in FSDC.

\section{Discussion}

Because DC have a crucial role in ACD, it is important to elucidate the mechanisms involved in DC maturation, which occurs during the sensitization process. In this work, we evaluated the effect of LPS, skin sensitizers and irritants on Trx-1 protein expression using the cell line FSDC as an experimental model of skin DC. We also evaluated whether $\mathrm{H}_{2} \mathrm{O}_{2}$, an activator of Trx-1, also increased CD86 protein expression. In addition, we studied the role of different signalling pathways on Trx-1 protein modulation induced by LPS, a well known inducer of DC maturation.

Analysing the effect of LPS, the skin sensitizers DNFB, PPD and $\mathrm{NiSO}_{4}$, and the irritants SDS and BC on Trx-1 protein levels we demonstrated that LPS and all the chemicals used increased the Trx-1 protein levels, after $24 \mathrm{~h}$ of FSDC stimulation (Fig. 1). However, after $48 \mathrm{~h}$ of FSDC stimulation, only LPS and skin sensitizers increased Trx-1 protein levels, mainly in cytoplasm, whereas the irritants had no effect (Figs. 2, 3). The similar pattern of Trx-1 protein levels obtained in FSDC and MoDC (Fig. 1) indicates that the FSDC cell line could be a good model for the study of DC maturation mechanisms. Accordingly, we have previously demonstrated that FSDC cell line and DC derived from human peripheral blood monocytes respond in a similar way to contact sensitizers by upregulating the proteins CXCR4 and CD40 [43]. In addition, we recently published that, in FSDC, LPS induces a maturation programme similar to that described in other DC models, namely activation of $\mathrm{NF}-\kappa \mathrm{B}, \mathrm{MAPK}$ and Akt, upregulation of co-stimulatory molecules and also production of the cytokines IL-6, CCL5, G-CSF, CCL2 and CXCL2 [44].

The increase in cytoplasmatic Trx-1 protein levels induced by LPS and skin sensitizers, after $48 \mathrm{~h}$ of FSDC stimulation, indicate that $\operatorname{Trx}-1$, due to its functions in defence against oxidative stress, activation of transcription factors (NF- $\kappa \mathrm{B}, \mathrm{Nrf} 2, \mathrm{AP}-1$ and p53), and also direct inhibition of ASK1 [8, 21, 36, 51, 65], could be partially responsible for the phenotypical and functional changes occurring during DC maturation and, consequently, in skin sensitization. Reinforcing the role of Trx-1 in skin sensitization, it was previously reported that upon DC cross talk with T cells, LPS and TNF- $\alpha$ induce DC Trx synthesis and its release providing a reducing microenvironment that facilitates immune response [6]. 

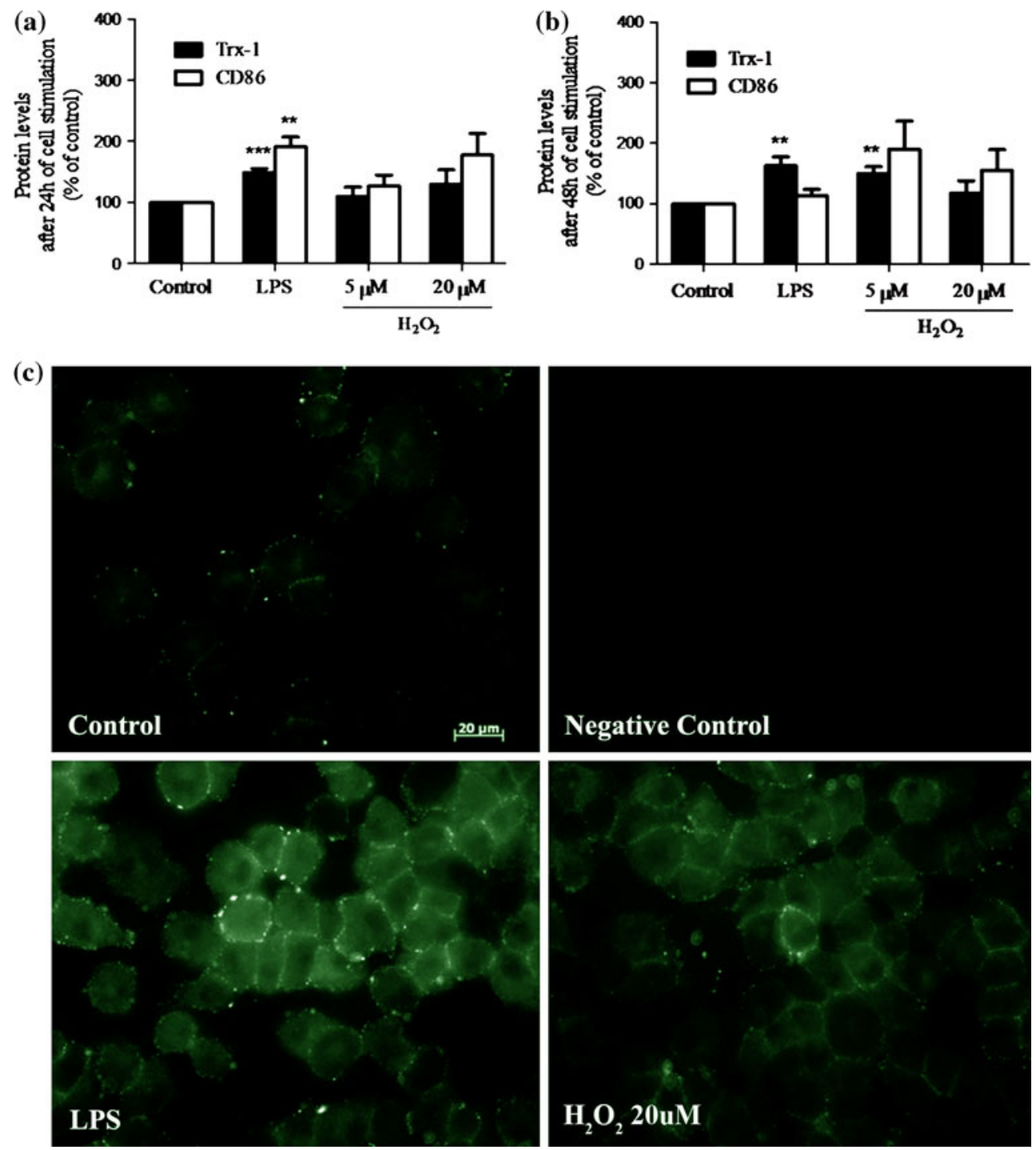

Fig. 5 Modulation of Trx-1 and CD86 protein levels by LPS and the activator of Trx-1 protein expression, $\mathrm{H}_{2} \mathrm{O}_{2}$. FSDC was incubated in culture medium in the absence (control), or in the presence of $5 \mu \mathrm{g} / \mathrm{ml}$ LPS, or $\mathrm{H}_{2} \mathrm{O}_{2}(5$ or $20 \mu \mathrm{M})$, for $24 \mathrm{~h}(\mathbf{a})$ or $48 \mathrm{~h}(\mathbf{b})$. Total cell extracts were electrophoresed through SDS-PAGE, transferred to PVDF membranes and subjected to Western blot analysis using an anti-Trx-1 antibody or an anti-CD86 antibody. The blots were quantified and the results were expressed as $\%$ of protein levels relatively to the control.

To investigate whether Trx-1 protein levels increase induced by LPS and skin sensitizers was due to an increase in Trx-1 mRNA expression, we performed real-time PCR analysis after $24 \mathrm{~h}$ of cell stimulation (Fig. 4). In accordance with other studies performed in other DC models $[45,55]$, LPS increased the Trx-1 mRNA expression in FSDC. $\mathrm{NiSO}_{4}$ also increased the Trx-1 mRNA expression in our DC model. This increase in Trx-1 mRNA expression could explain the effect of LPS and $\mathrm{NiSO}_{4}$ on Trx-1 protein levels, which was upregulated after 24 and $48 \mathrm{~h}$ of cell stimulation (Figs. 1,2). DNFB and SDS had no effect on
Each value represents the mean \pm SEM of three to nine independent experiments and the results were statistically compared using Student's $t$ test $(* * P<0.01, * * * P<0.001$, as compared to the control situation). c FSDC was incubated in culture medium in the absence (control), or in the presence of $5 \mu \mathrm{g} / \mathrm{ml} \mathrm{LPS}$, or $20 \mu \mathrm{M} \mathrm{H}_{2} \mathrm{O}_{2}$, for $24 \mathrm{~h}$, and then subjected to immunostaining, without permeabilization, using an anti-CD86 antibody. The images shown are representative of two individual experiments yielding similar results (magnification $\times 630$ )

Trx-1 mRNA expression. Based on these results, we can conclude that the increase in Trx-1 protein levels induced by LPS and $\mathrm{NiSO}_{4}$ is, at least in part, due to an increase in Trx-1 mRNA expression.

As described above, Trx-1 has an important role in defence against cellular oxidative stress, which could be induced by skin sensitizers due to its electrophilic properties $[12,22]$. It was also demonstrated that the redox imbalance induced by skin sensitizers is important in the regulation of DC functions [5, 38, 39, 41, 47, 61]. Therefore, the increase in Trx-1 mRNA expression observed in 
(a)
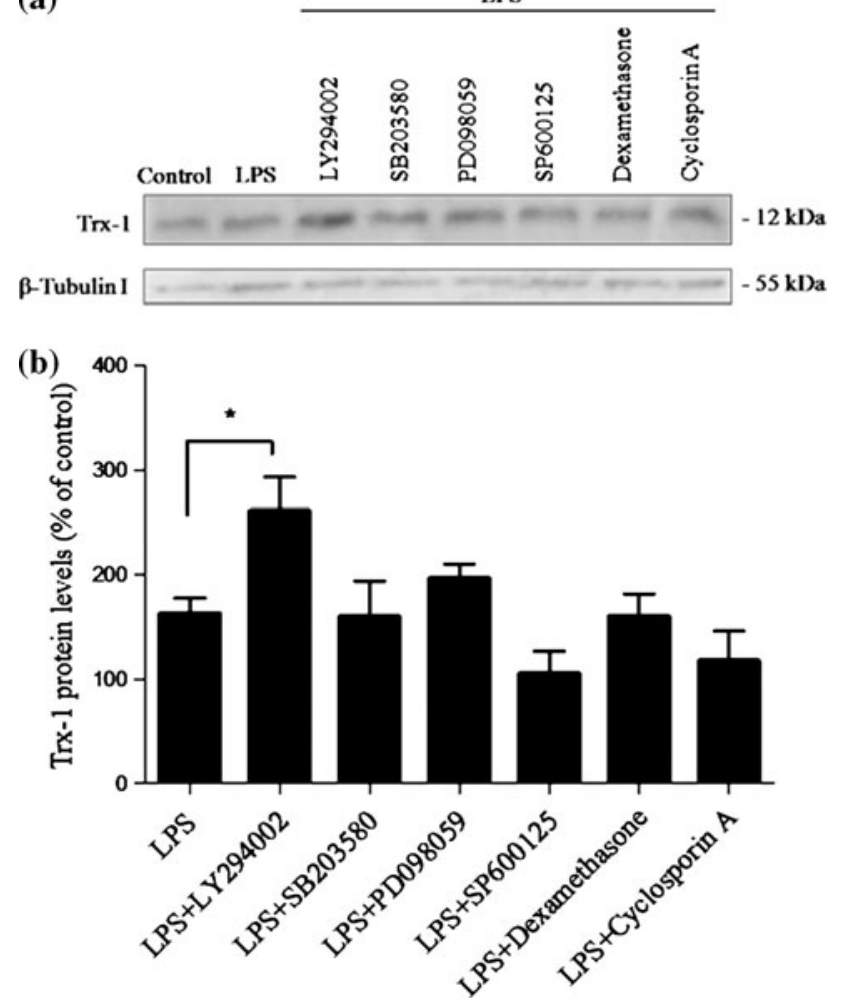

Fig. 6 Intracellular signalling pathways involved in Trx-1 protein levels modulation induced by LPS in FSDC. a FSDC was incubated in the presence of $5 \mu \mathrm{g} / \mathrm{ml}$ LPS alone or with PI3K inhibitor LY294002 $(2.5 \mu \mathrm{M})$, p38 MAPK inhibitor SB203580 $(20 \mu \mathrm{M})$, ERK1/2 activation inhibitor PD098059 $(20 \mu \mathrm{M})$, JNK inhibitor SP600125 $(1 \mu \mathrm{M})$ or with the immunomodulators dexamethasone $(5 \mu \mathrm{M})$, or cyclosporin $\mathrm{A}$ $(1 \mu \mathrm{M})$, for $48 \mathrm{~h}$. Total cell extracts were electrophoresed through SDS-PAGE, transferred to PVDF membranes and subjected to Western blot analysis using an anti-Trx-1 antibody. To ensure that there were similar amounts of protein in each sample, the membranes were stripped, and reprobed with a monoclonal anti- $\beta$-tubulin I antibody $(1: 20,000)$ followed by incubation with an alkaline phosphatase-conjugated anti-mouse antibody $(1: 20,000)$. b The blots were quantified and the results were expressed as \% of Trx-1 protein levels relatively to the control. Each value represents the mean \pm SEM of three to four independent experiments. The results were statistically compared using one-way ANOVA test, with Dunnett's post test $(* P<0.05)$

FSDC is probably a cellular response to redox imbalance. The expression of Trx genes is regulated by the transcription factor Nrf2/ARE regulatory pathway, one of the most important cellular defence mechanism against oxidative stress or electrophiles [29, 67]. Hence, our results support the utilisation of Nrf2/ARE regulatory pathway to screen the sensitization potential of novel chemicals, as recently proposed [1, 42]. Accordingly, it was previously demonstrated that the skin sensitizer Ni (II) could activate the Nrf2 signalling pathway in human monocytic cells [33].

To establish a correlation between thioredoxin-1 expression and DC maturation, we used the activator of thioredoxin-1, hydrogen peroxide [49], and addressed its role on
CD86 expression, a conventional marker of DC maturation [20], and recently demonstrated by us to be upregulated in a mouse skin DC line by LPS [44]. We observed that the $\mathrm{H}_{2} \mathrm{O}_{2}$ concentration that increased Trx-1 protein expression also augmented CD86 on the surface level, reinforcing the involvement of Trx-1 in DC maturation.

Lipopolysaccharide has been shown to fully activate DC both in vitro and in vivo [13, 18,60]. We have recently demonstrated that LPS activates Akt, NF- $\kappa \mathrm{B}$ and MAPK, namely JNK1/2, ERK1/2 and p38 MAPK, in FSDC [44]. Therefore, stimulation with LPS could be used as a model to elucidate the intracellular signalling pathways involved in DC maturation, a crucial step for skin sensitization. Using specific inhibitors of PI3K-Akt (LY294002), p38 MAPK (SB203580), ERK1/2 (PD098059) and JNK1/2 (SP600125), we further investigated the intracellular signalling pathways involved in the increase of Trx-1 protein levels induced by LPS. We observed that the PI3K-Akt signalling pathway, and not the MAPK signalling pathways, is involved in the modulation, particularly the inhibition, of Trx-1 protein levels induced by LPS in FSDC (Fig. 5). In agreement, it was previously demonstrated that the activation of different signalling pathways and the induction of gene expression in LPS-treated monocytes was negatively regulated by the PI3K-Akt signalling pathway [25]. The immunosuppressors and inhibitors of the transcription factor NF- $\kappa \mathrm{B}$, dexamethasone and cyclosporin $\mathrm{A}$, did not modify Trx-1 protein levels induced by LPS.

Our results indicate that LPS increased Trx-1 protein levels, partially due to an increase in Trx-1 mRNA expression, being the Nrf2/ARE regulatory pathway probably involved. In addition, the PI3K-Akt signalling pathway has an inhibitory role in this cell response to LPS. Based on our results and previous studies, we propose a possible cellular mechanism, by which LPS modulates the Trx-1 protein levels in FSDC. LPS is recognised by a LPS-activation cluster [56] that could activate two different pathways. Upon stimulation with LPS, ROS production occurs [39, 62], which appears to break the inactive complex reduced Trx-1/ASK1, thus allowing the subsequent recruitment of TRAF6 to the ASK1 signalosome [21, 54]. The activated ASK1 signalosome induces Nrf2/ ARE-mediated expression [66], which is involved in Trx1 protein expression $[29,67]$. On the other hand, LPS activates PI3K-Akt signalling pathway $[7,44]$ that have an inhibitory role in ASK1/Nrf2/ARE-mediated Trx-1 expression, which is due to ASK1 phosphorylation that downregulates its activity [30,53]. Therefore, LPS modulates Trx-1 protein expression by two opposite mechanisms: increases Trx-1 protein expression by activating the ASK1/Nrf2/ARE pathway, and inhibits Trx-1 protein expression by activating the PI3K-Akt pathway. Interestingly, the PI3K-Akt signalling pathway could be redox 
regulated through the interaction between Trx-1 and the phosphatase PTEN [21, 32, 34].

Similarly to LPS, skin sensitizers can induce redox imbalance $[38,41]$ that activates the cellular mechanism proposed above and responsible for the increase in Trx-1 protein levels. These data suggest that the ASK1/Nrf2/ ARE regulatory pathway could be activated by LPS and skin sensitizers in a similar way, being involved in DC maturation.

In conclusion, using FSDC as a cell model, our results suggest that LPS, skin sensitizers and irritants modulate Trx-1 protein levels by different pathways in DC. Based on the results obtained for the maturation agent LPS, we discussed the possible mechanism by which LPS, skin sensitizers and irritants differentially modulate Trx- 1 protein levels and, therefore, induce different phenotypical and functional changes in DC. It can be stated that the analysis of Trx-1 redox state or protein expression and the signalling pathways involved in Trx-1 expression could be helpful in elucidating DC maturation process and, therefore, in understanding mechanisms involved in the acquisition of ACD. However, further research is needed to identify the early intracellular mechanisms involved in chemical-induced DC maturation, as well as the cross talk between different signalling pathways, to clarify the molecular mechanisms associated with the induction of skin sensitization.

Acknowledgments We thank Dr G. Girolomoni (Laboratory of Immunology, Istituto Dermopatico dell'Immacolata, IRCCS, Rome, Italy) for the kind gift of the foetal skin-derived dendritic cell line (FSDC). This work was supported by a project from Foundation for Science and Technology (FCT) (PTDC/SAU-OSM/099762/2008) and by a FCT Ph.D. fellowship (SFRH/30563/2006).

Conflict of interest statement None of the authors have any conflict of interest.

\section{References}

1. Ade N, Leon F, Pallardy M et al (2009) HMOX1 and NQO1 genes are upregulated in response to contact sensitizers in dendritic cells and THP-1 cell line: role of the Keap1/Nrf2 pathway. Toxicol Sci 107:451-460

2. Aiba S, Katz SI (1990) Phenotypic and functional characteristics of in vivo-activated Langerhans cells. J Immunol 145:2791-2796

3. Aiba S, Terunuma A, Manome H et al (1997) Dendritic cells differently respond to haptens and irritants by their production of cytokines and expression of co-stimulatory molecules. Eur J Immunol 27:3031-3038

4. Aiba S, Manome H, Nakagawa S et al (2003) p38 Mitogen-activated protein kinase and extracellular signal-regulated kinases play distinct roles in the activation of dendritic cells by two representative haptens, $\mathrm{NiCl} 2$ and 2, 4-dinitrochlorobenzene. J Invest Dermatol 120:390-399

5. Alderman CJ, Shah S, Foreman JC et al (2002) The role of advanced oxidation protein products in regulation of dendritic cell function. Free Radic Biol Med 32:377-385
6. Angelini G, Gardella S, Ardy M et al (2002) Antigen-presenting dendritic cells provide the reducing extracellular microenvironment required for T lymphocyte activation. Proc Natl Acad Sci USA 99:1491-1496

7. Ardeshna KM, Pizzey AR, Devereux S et al (2000) The PI3 kinase, p38 SAP kinase, and NF-kappaB signal transduction pathways are involved in the survival and maturation of lipopolysaccharide-stimulated human monocyte-derived dendritic cells. Blood 96:1039-1046

8. Arner ES, Holmgren A (2000) Physiological functions of thioredoxin and thioredoxin reductase. Eur J Biochem 267:6102-6109

9. Arrighi JF, Rebsamen M, Rousset F et al (2001) A critical role for p38 mitogen-activated protein kinase in the maturation of human blood-derived dendritic cells induced by lipopolysaccharide, TNF-alpha, and contact sensitizers. J Immunol 166:3837-3845

10. Banchereau J, Steinman RM (1998) Dendritic cells and the control of immunity. Nature 392:245-252

11. Bertini R, Howard OM, Dong HF et al (1999) Thioredoxin, a redox enzyme released in infection and inflammation, is a unique chemoattractant for neutrophils, monocytes, and T cells. J Exp Med 189:1783-1789

12. Corsini E, Kimber I (2007) Factors governing susceptibility to chemical allergy. Toxicol Lett 168:255-259

13. Coutant KD, de Fraissinette AB, Cordier A et al (1999) Modulation of the activity of human monocyte-derived dendritic cells by chemical haptens, a metal allergen, and a staphylococcal superantigen. Toxicol Sci 52:189-198

14. Cruz MT, Duarte CB, Goncalo M et al (2001) LPS induction of I kappa B-alpha degradation and iNOS expression in a skin dendritic cell line is prevented by the janus kinase 2 inhibitor, Tyrphostin b42. Nitric Oxide 5:53-61

15. Cruz MT, Duarte CB, Goncalo M et al (2002) Differential activation of nuclear factor kappa B subunits in a skin dendritic cell line in response to the strong sensitizer 2, 4-dinitrofluorobenzene. Arch Dermatol Res 294:419-425

16. Cruz MT, Goncalo M, Paiva A et al (2005) Contact sensitizers downregulate the expression of the chemokine receptors CCR6 and CXCR4 in a skin dendritic cell line. Arch Dermatol Res 297:43-47

17. Cruz MT, Neves BM, Goncalo M et al (2007) Effect of skin sensitizers on inducible nitric oxide synthase expression and nitric oxide production in skin dendritic cells: role of different immunosuppressive drugs. Immunopharmacol Immunotoxicol 29:225-241

18. De Smedt T, Pajak B, Muraille E et al (1996) Regulation of dendritic cell numbers and maturation by lipopolysaccharide in vivo. J Exp Med 184:1413-1424

19. Divkovic M, Pease CK, Gerberick GF et al (2005) Hapten-protein binding: from theory to practical application in the in vitro prediction of skin sensitization. Contact Dermatitis 53:189-200

20. Dowling D, Hamilton CM, O’Neill SM (2008) A comparative analysis of cytokine responses, cell surface marker expression and MAPKs in DCs matured with LPS compared with a panel of TLR ligands. Cytokine 41:254-262

21. Fujino G, Noguchi T, Takeda K et al (2006) Thioredoxin and protein kinases in redox signaling. Semin Cancer Biol 16:427-435

22. Gerberick GF, Vassallo JD, Bailey RE et al (2004) Development of a peptide reactivity assay for screening contact allergens. Toxicol Sci 81:332-343

23. Gildea LA, Ryan CA, Foertsch LM et al (2006) Identification of gene expression changes induced by chemical allergens in dendritic cells: opportunities for skin sensitization testing. J Invest Dermatol 126:1813-1822

24. Girolomoni G, Lutz MB, Pastore S et al (1995) Establishment of a cell line with features of early dendritic cell precursors from fetal mouse skin. Eur J Immunol 25:2163-2169 
25. Guha M, Mackman N (2002) The phosphatidylinositol 3-kinaseAkt pathway limits lipopolysaccharide activation of signaling pathways and expression of inflammatory mediators in human monocytic cells. J Biol Chem 277:32124-32132

26. Hulette BA, Ryan CA, Gerberick GF (2002) Elucidating changes in surface marker expression of dendritic cells following chemical allergen treatment. Toxicol Appl Pharmacol 182:226-233

27. Hulette BC, Ryan CA, Gildea LA et al (2005) Relationship of CD86 surface marker expression and cytotoxicity on dendritic cells exposed to chemical allergen. Toxicol Appl Pharmacol 209:159-166

28. Jugde F, Boissier C, Rougier-Larzat N et al (2005) Regulation by allergens of chemokine receptor expression on in vitro-generated dendritic cells. Toxicology 212:227-238

29. Kensler TW, Wakabayashi N, Biswal S (2007) Cell survival responses to environmental stresses via the Keap1-Nrf2-ARE pathway. Annu Rev Pharmacol Toxicol 47:89-116

30. Kim AH, Khursigara G, Sun X et al (2001) Akt phosphorylates and negatively regulates apoptosis signal-regulating kinase 1 . Mol Cell Biol 21:893-901

31. Koeper LM, Schulz A, Ahr HJ et al (2007) In vitro differentiation of skin sensitizers by cell signaling pathways. Toxicology 242:144-152

32. Leslie NR, Bennett D, Lindsay YE et al (2003) Redox regulation of PI 3-kinase signalling via inactivation of PTEN. EMBO J 22:5501-5510

33. Lewis JB, Messer RL, McCloud VV et al (2006) Ni(II) activates the Nrf2 signaling pathway in human monocytic cells. Biomaterials 27:5348-5356

34. Luyendyk JP, Schabbauer GA, Tencati M et al (2008) Genetic analysis of the role of the PI3K-Akt pathway in lipopolysaccharide-induced cytokine and tissue factor gene expression in monocytes/macrophages. J Immunol 180:4218-4226

35. Martin SF, Merfort I, Thierse HJ (2006) Interactions of chemicals and metal ions with proteins and role for immune responses. Mini Rev Med Chem 6:247-255

36. Masutani H, Ueda S, Yodoi J (2005) The thioredoxin system in retroviral infection and apoptosis. Cell Death Differ 12(Suppl 1):991-998

37. Matos TJ, Duarte CB, Goncalo M et al (2005) DNFB activates MAPKs and upregulates CD40 in skin-derived dendritic cells. J Dermatol Sci 39:113-123

38. Matos TJ, Duarte CB, Goncalo M et al (2005) Role of oxidative stress in ERK and p38 MAPK activation induced by the chemical sensitizer DNFB in a fetal skin dendritic cell line. Immunol Cell Biol 83:607-614

39. Matsue H, Edelbaum D, Shalhevet D et al (2003) Generation and function of reactive oxygen species in dendritic cells during antigen presentation. J Immunol 171:3010-3018

40. Miyazawa M, Ito Y, Kosaka N et al (2008) Role of MAPK signaling pathway in the activation of dendritic type cell line, THP-1, induced by DNCB and NiSO4. J Toxicol Sci 33:51-59

41. Mizuashi M, Ohtani T, Nakagawa S et al (2005) Redox imbalance induced by contact sensitizers triggers the maturation of dendritic cells. J Invest Dermatol 124:579-586

42. Natsch A, Emter R (2008) Skin sensitizers induce antioxidant response element dependent genes: application to the in vitro testing of the sensitization potential of chemicals. Toxicol Sci 102:110 119

43. Neves BM, Cruz MT, Francisco V et al (2008) Differential modulation of CXCR4 and CD40 protein levels by skin sensitizers and irritants in the FSDC cell line. Toxicol Lett 177:74-82

44. Neves BM, Cruz MT, Francisco V et al (2009) Differential roles of PI3-Kinase, MAPKs and NF-kappaB on the manipulation of dendritic cell $\mathrm{T}(\mathrm{h}) 1 / \mathrm{T}(\mathrm{h}) 2$ cytokine/chemokine polarizing profile. Mol Immunol 46:2481-2492
45. Pereira SR, Faca VM, Gomes GG et al (2005) Changes in the proteomic profile during differentiation and maturation of human monocyte-derived dendritic cells stimulated with granulocyte macrophage colony stimulating factor/interleukin-4 and lipopolysaccharide. Proteomics 5:1186-1198

46. Rescigno M, Martino M, Sutherland CL et al (1998) Dendritic cell survival and maturation are regulated by different signaling pathways. J Exp Med 188:2175-2180

47. Rutault K, Alderman C, Chain BM et al (1999) Reactive oxygen species activate human peripheral blood dendritic cells. Free Radic Biol Med 26:232-238

48. Ryan CA, Gildea LA, Hulette BC et al (2004) Gene expression changes in peripheral blood-derived dendritic cells following exposure to a contact allergen. Toxicol Lett 150:301-316

49. Sachi Y, Hirota K, Masutani $\mathrm{H}$ et al (1995) Induction of ADF/ TRX by oxidative stress in keratinocytes and lymphoid cells. Immunol Lett 44:189-193

50. Saint-Mezard P, Rosieres A, Krasteva M et al (2004) Allergic contact dermatitis. Eur J Dermatol 14:284-295

51. Saitoh M, Nishitoh H, Fujii M et al (1998) Mammalian thioredoxin is a direct inhibitor of apoptosis signal-regulating kinase (ASK) 1. EMBO J 17:2596-2606

52. Straube F, Grenet O, Bruegger $P$ et al (2005) Contact allergens and irritants show discrete differences in the activation of human monocyte-derived dendritic cells: consequences for in vitro detection of contact allergens. Arch Toxicol 79:37-46

53. Sumbayev VV (2008) PI3 kinase and direct S-nitrosation are involved in down-regulation of apoptosis signal-regulating kinase 1 during LPS-induced Toll-like receptor 4 signalling. Immunol Lett 115:126-130

54. Takeda K, Noguchi T, Naguro I et al (2008) Apoptosis signal-regulating kinase 1 in stress and immune response. Annu Rev Pharmacol Toxicol 48:199-225

55. Tang Z, Saltzman A (2004) Understanding human dendritic cell biology through gene profiling. Inflamm Res 53:424-441

56. Triantafilou M, Triantafilou K (2002) Lipopolysaccharide recognition: CD14, TLRs and the LPS-activation cluster. Trends Immunol 23:301-304

57. Trompezinski S, Migdal C, Tailhardat M et al (2008) Characterization of early events involved in human dendritic cell maturation induced by sensitizers: cross talk between MAPK signalling pathways. Toxicol Appl Pharmacol 230:397-406

58. Tuschl H, Kovac R, Weber E (2000) The expression of surface markers on dendritic cells as indicators for the sensitizing potential of chemicals. Toxicol In Vitro 14:541-549

59. Vandesompele J, De Preter K, Pattyn F et al (2002) Accurate normalization of real-time quantitative RT-PCR data by geometric averaging of multiple internal control genes. Genome Biol 3:RESEARCH0034.1-0034.11

60. Verhasselt V, Buelens C, Willems F et al (1997) Bacterial lipopolysaccharide stimulates the production of cytokines and the expression of costimulatory molecules by human peripheral blood dendritic cells: evidence for a soluble CD14-dependent pathway. J Immunol 158:2919-2925

61. Verhasselt V, Goldman M, Willems F (1998) Oxidative stress upregulates IL- 8 and TNF-alpha synthesis by human dendritic cells. Eur J Immunol 28:3886-3890

62. Verhasselt V, Vanden Berghe W, Vanderheyde N et al (1999) Nacetyl-L-cysteine inhibits primary human $\mathrm{T}$ cell responses at the dendritic cell level: association with NF-kappaB inhibition. J Immunol 162:2569-2574

63. Vital AL, Goncalo M, Cruz MT et al (2003) Dexamethasone prevents granulocyte-macrophage colony-stimulating factor-induced nuclear factor-kappaB activation, inducible nitric oxide synthase expression and nitric oxide production in a skin dendritic cell line. Mediators Inflamm 12:71-78 
64. Vital AL, Goncalo M, Cruz MT et al (2004) The sensitizers nickel sulfate and 2, 4-dinitrofluorobenzene increase CD40 and IL-12 receptor expression in a fetal skin dendritic cell line. Biosci Rep 24:191-202

65. Watson WH, Yang X, Choi YE et al (2004) Thioredoxin and its role in toxicology. Toxicol Sci 78:3-14
66. Yu R, Chen C, Mo YY et al (2000) Activation of mitogenactivated protein kinase pathways induces antioxidant response element-mediated gene expression via a Nrf2-dependent mechanism. J Biol Chem 275:39907-39913

67. Zhang DD (2006) Mechanistic studies of the Nrf2-Keap1 signaling pathway. Drug Metab Rev 38:769-789 